\title{
Gender as a mediator in the perception of speech rate
}

\author{
STANLEY FELDSTEIN \\ University of Maryland Baltimore County, Baltimore, Maryland \\ FAITH-ANNE DOHM \\ University of Connecticut, Storrs, Connecticut \\ and \\ CYNTHIA L. CROWN \\ Xavier University, Cincinnati, Ohio
}

\begin{abstract}
The perception of speech rate was examined as a function of the gender of the speakers and listeners and the speech rate of the listeners. In the first experiment, the stimuli were moderately paced speech samples from women, with males and females as listeners. The results indicated that although the speech rates of the female listeners were positively related to perceived speech rate, the rates of the male listeners were negatively related. In the second experiment, the stimuli were comparably paced samples of male and female speech, again with men and women as the listeners. The results indicated that the women judged the speech rates of all the speakers to be faster than did the men, and that all the listeners believed that the men talked faster than the women. The results of both studies suggest that gender plays an influential role in the perception of speech rate.
\end{abstract}

The perception of global speech rate has been used as both a dependent and an independent variable in psychological research and practice. It has been found, for example (Miller, Maruyama, Beaber, \& Valone, 1976), that speech rate influences the degree to which speakers are considered to be persuasive, intelligent, knowledgeable, and objective. The influence of speech rate on interpersonal attributions has also been examined (Apple, Streeter, \& Krauss, 1979; Brown, Strong, \& Rencher, 1974; Smith, Brown, Strong, \& Rencher, 1975; Street \& Brady, 1982; Street, Brady, \& Putman, 1983). Psychodiagnosticians attend to speech rate to help them determine not only whether an individual is depressed or manic, but whether the illness is bipolar or unipolar (Anderson \& Jaffe, 1990). Speech rate also plays an important role in the assessment of type A behavior (see, e.g., Dembroski \& MacDougall, 1983; Schucker \& Jacobs, 1977; Siegman, Feldstein, Tommaso, Ringel, \& Lating, 1987) and in the mediation of cardiovascular responsivity (Kearns \& Feldstein,1987). Finally, it is related to the detection of emotional states and extraversion (Feldstein \& Sloan, 1984; Scherer, 1974).

The two experiments presented here are part of a series of studies by the authors and their colleagues, who

The authors are indebted to the Multi-Media Learning Center and to the Academic Computing Center of the University of Maryland Baltimore County for making their time and facilities so readily available. They are grateful to Sallie Simpson, who served as the experimenter in the first study, and to Terri Harold, who edited the final draft of the manuscript. Requests for reprints should be sent to $S$. Feldstein, Department of Psychology, University of Maryland Baltimore County, Baltimore, MD 21228. are concerned with the perception of speech rate and the role of such perception in social evaluation. The series has taken three directions, the first of which has been to investigate the influence of the acoustical components of speech on the perception of speech rate. Previous investigators (e.g., Goldman-Eisler, 1968; Grosjean \& Lane, 1974) had cumulatively demonstrated that the perception of speech rate is a function of at least three characteristics of the stream of speech: variations in articulation rate, the number of pauses, and the duration of pauses. Our studies (Bond \& Feldstein, 1982; Bond, Feldstein, \& Simpson, 1988) added two more characteristics: variations in vocal frequency (pitch), and vocal intensity (loudness). Although our successive studies spanned the course of a decade, we knew of only one other study (Apple, 1981) that was especially relevant to our effort. It yielded the serendipitous finding that increasing and decreasing the vocal frequency of a speech sample by $20 \%$ produced monotonic changes in the perceived rate of speech.

The second direction is concerned with the effects of perceiver (listener) characteristics on the perception of speech rate (Feldstein, Crown, \& Jaffe, 1991), and the third, with the role of speech rate in social evaluation or person perception (Dohm, Feldstein, \& Crown, 1988). The two experiments presented here are relevant to the second direction; they were designed to explore the possibility that the perception of speech rate is influenced not simply by characteristics of the speech stream, but also by characteristics of the speakers and listeners. In the first experiment, we asked whether the speech rates of the listeners affected their perceptions of speech rate. A sur- 
prising result was that gender appeared to have mediated the effect of the listeners' rates on their judgments of the speakers' rates. Thus, in a second experiment, we tested the hypothesis that the listeners' gender as well as their speech rates influence their perceptions of speech rate.

\section{EXPERIMENT 1}

Although numerous studies have shown that speech rate influences how speakers are perceived by others, in virtually no studies has the role of the perceivers' personal attributes in their perception of speech been examined. If the perception of speech rate is differentially influenced by perceiver characteristics, then how we perceive other individuals depends, in part, on how those characteristics influence our perception of their speech rates. The findings of Street et al. (1983) suggested that there may be a relationship between the speech rates of perceivers and their perceptions of other persons' speech rates. However, the nature of that relationship was never directly assessed. It seemed intuitively reasonable to conjecture in this first experiment that individuals who speak rapidly tend to perceive others as speaking slowly and that individuals who speak slowly tend to perceive others as speaking rapidly. Given that there is also suggestive evidence (Feldstein et al., 1991) that gender and extraversion may influence the perception of speech rate, both were included as control variables.

\section{Method}

The study was conducted in a language laboratory containing rows of desks equipped with stereo headphones and microphones, all of the same make and model, connected to an audiocassette deck in a central control unit. This made it possible to play the stimulus material at all the desks simultaneously and to ensure that the reception characteristics were the same for all the headphones.

The listeners were 23 male and 30 female university undergraduates. They were asked to judge the rates of each of ten 1-min samples of moderately paced speech on a 10-point scale ranging from very slow (1) to very fast (10). The 10 samples, the words per minute (WPM) of which averaged $156.5(S D=40.0)$, had been excised from the responses of each of 10 different women to the same three TAT (Murray, 1943) cards. ${ }^{1}$ All the samples had been recorded on a single audiotape and were separated from one another by $20 \mathrm{sec}$ of silence. Prior to rating the speech samples, the listeners heard recorded instructions and completed one practice sample.

After judging the 10 samples, each listener was asked to talk for $2 \mathrm{~min}$ about one or more of the topics presented to him/her by the investigator. Upon the completion of this task (which was recorded electronically), the listeners were asked to complete the Extraversion Scale (ES) of the Eysenck Personality Inventory (EPI). A total score, plus a score for each of its two factors, impulsiveness and sociability (S. Eysenck \& H. Eysenck, 1963), were derived from the scale. The recorded speech samples of the listeners were subsequently transcribed and scored for WPM.

Four scores were computed for each of the listeners: (1) the average of the ratings of the 10 speech samples; (2) the score on the Sociability subscale of the ES; (3) the score on the Impulsiveness subscale of the ES; and (4) the WPM of the participant's own speech sample.

\section{Results}

The data were subjected to a hierarchical multiple regression analysis (Pedhazur, 1982) in which the dependent variable was perceived speech rate. The first set of independent variables included listener gender, impulsiveness scores, and sociability scores, none of which influenced perceived speech rate. The next variable to enter the equation, the listeners' WPM, was also found not to be significantly related to the dependent variable $[F(1,49)>1]$.

The last set of variables to enter comprised the products of gender and WPM, impulsiveness and WPM, and sociability and WPM. These products, by virtue of their order in the equation, "carry" the effects of the interactions between the pairs of variables involved as they relate to perceived speech rate. The analysis yielded only one significant result, which was the interaction of gender and WPM $\left[F(1,47)=4.041, p=.05, r^{2}=.06\right]$. Although the speech rates of the female listeners were positively related to perceived speech rate, the speech rates of the male listeners were negatively related to the perceived rate (Figure 1).

It might be noted that the probability that the $F$ ratio indexing the joint influence of gender and sociability on perceived tempo $\left[F(1,46)=3.640, r^{2}=.05\right]$ could have occurred by chance is about .06 . The effect was such that the more sociable male listeners tended to perceive the stimulus speech as faster in tempo than did the less sociable males, whereas the opposite was true for the sociable female listeners.

The judgments of speech rate made by the listeners averaged $4.4(S D=.8)$, and the listeners' own speech rates averaged 158.7 WPM $(S D=30.8)$. The total scores on the Extraversion scale were significantly related to the listeners' WPM $[r(51)=.36]$, but of its two factors, only impulsiveness correlated significantly with their WPM $[r(51)=.30]$.

\section{Discussion}

The results of the study provide no evidence of a direct relation between the speech rates of the listeners and their perceptions of the speech rates of others. Instead, the results imply that the relation between the perceived rates of speech and the perceivers' rates of speech was mediated by their gender. The women who themselves spoke quickly judged the rates of the speech samples to be faster than did the women who spoke slowly. Conversely, the men who spoke quickly judged the rates

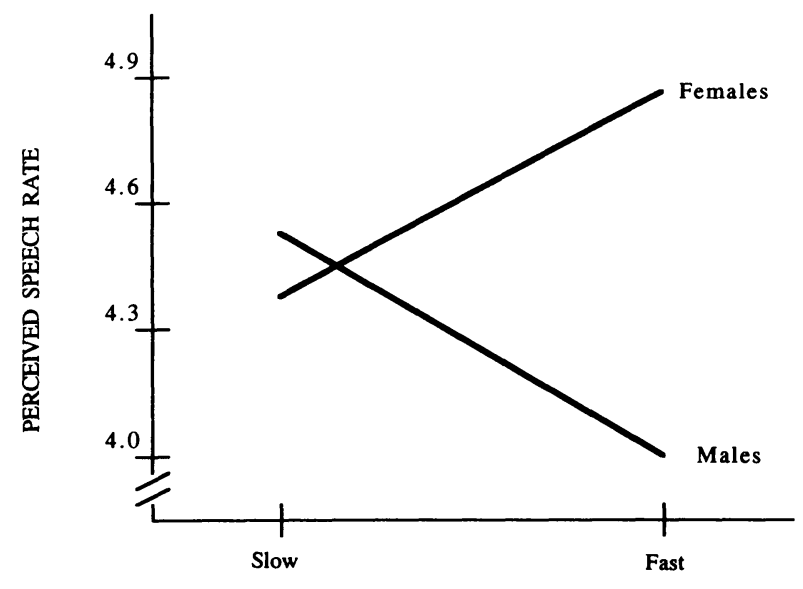

LISTENER SPEECH RATE

Figure 1. The interaction of listener speech rate with listener gender: The relation between listener speech rate and perceived speech rate depends on whether the listeners are males or females. 
of the samples to be slower than did the men who spoke slowly. It should be noted that the stimulus samples were all the voices of women, and it may be that the perception of the voices of one's own gender differs from the perception of voices of the opposite gender. Another possibility is that the difference represents an "ingroup/outgroup" effect because of our using only female voices. According to current schema theory, and even older theories about group-versus-self distinctions (e.g., those of Bourhis \& Giles, 1977, and Tajfel, 1982), the males may have considered the female speakers, simply by virtue of their gender, to be an "outgroup" and, therefore, different from themselves, whereas the female judges considered the female speakers to be part of their own group-part of the "ingroup,"' so to speak-and thus to be similar to themselves. One implication of such a notion is that the behavior of the "outgroup" is perceived differently from that of the "ingroup."

It was expected (Feldstein \& Sloan, 1984) that the listeners' degrees of extraversion would be related to their speech rates, but it was more interesting that, although not quite significant, gender seemed to mediate between the sociability of the listeners and their judgments of the stimulus speech rates.

\section{EXPERIMENT 2}

Given the results of Experiment 1, it seemed reasonable to ask whether the results would have been different had male voices been included as stimuli. Were the results an "ingroup/outgroup" effect, the inclusion of both male and female speech stimuli might be expected to yield an interaction of the listeners' speech rates and their gender with the gender of the speakers-that is, a triple interaction. This study, then, was a replication of Experiment 1, but with speech samples from males and females as stimuli.

However, the more important finding of the first experiment is that gender did play some role in the perception of speech rate. Despite the current concern with the influence of gender on a variety of social and perceptual tasks (see, e.g., Eagly, 1983; Hall, 1985), only one study (Bond et al., 1988) incorporated gender into its design. That study reported that pitch and speaker gender jointly influenced judgments of speaker rate, such that women who spoke with low-pitched voices, but not those with high-pitched voices, were judged to speak more slowly than men. Thus, another aim of this second experiment was to determine whether gender, alone or in interaction, plays a role in the perception of speech rate.

\section{Method}

The experiment was conducted in the same language laboratory as was Experiment 1. A 1-min speech sample was excised from the responses of each of five males and five females to the same three TAT cards. Of these 10 samples, however, only three male and three female samples were selected for the experiment. The purpose of the selection was to obtain male and female stimuli that were comparable in terms of their average WPM. The WPM of the males averaged 141.67 (SD = $14.57)$; those of the females averaged $143.67(S D=12.34)$. All the samples were recorded on a single cassette tape with $20 \mathrm{sec}$ of silence between successive samples.

Twenty-three male and 28 female university undergraduates volunteered to participate and came to the laboratory in groups of 2-9. Prior to rating the speech samples, they listened to recorded instructions and completed one practice rating. After hearing each of the six samples, the listeners judged its rate, using the 10-point scales that were used in Experiment 1. After hearing all six samples, the listeners completed the ES of the EPI. The Sociability and Impulsiveness components of the ES are among the few personality characteristics that have been demonstrated to discernibly affect behavior, especially speech behavior (see, e.g., Feldstein \& Sloan, 1984; Scherer, 1978). Thus, the ES was administered in order to control for possible confounding effects of the two components on the relation between the listeners' speech rates and their ratings of the stimulus speech. Finally, each listener was asked to provide a 2-min sample of his/her own speech.

Five scores were computed for each of the listeners. In addition to the two scores for the Sociability and Impulsiveness subscales of the ES, and the WPM of the listener's own speech sample, there were two others: the sum of the ratings of the three male speech samples, and the sum of the ratings of the three female speech samples.

\section{Results}

The data were subjected a hierarchical multiple regression analysis in which perceived speech rate was the dependent variable. The initial set of independent variables that were entered into the regression equation comprised the two subscale scores of the ES, which were treated as covariates. The next two variables that entered the equation as a set were the gender and speech rate of the listeners. The third set to enter was the product of listener gender and speech rate, which carried the effect of whatever interaction occurred between the two variables.

The five variables listed above were the betweensubjects variables, and they were followed by a criterion variable that carried the between-subjects error variance. The remaining variables that entered the equation were within-subjects variables, and the first of these was a coded factor denoting the gender of the speakers. The next set to enter contained two more variables: the product of listener and speaker gender and the product of speaker gender and the speech rate of the listeners. The last set to enter contained the triple product of the gender of the speakers and the listeners and the speech rate of the listeners. This product carried the triple interaction.

The analysis yielded two statistically significant effects. The gender of the listeners $[F(1,45)=4.182, p<.05$, $\left.r^{2}=.06\right]$ and the gender of the speakers $[F(1,47)=$ $\left.63.972, p<.001, r^{2}=.57\right]$ were each found to contribute significantly to the perception of speech rate. The first effect, that of listener gender, indicates that the female listeners judged the speech rates of all the speakers to be faster than did the male listeners. The second effect, that of speaker gender, indicates that all the listeners believed that the male speakers talked faster than did the female speakers.

\section{Discussion}

The results do not support the expectation that listener gender and speech rate interact with speaker gender in the perception of the speakers' rates. Nor did the results replicate the interaction of listener speech rate and gender obtained in the first experiment. Thus, it is unlikely that the perception of speech rate is influenced by "ingroup/outgroup" considerations.

What the results do suggest, however, is that listeners' perceptions of speech rate are influenced not only by their own gender, but also, and separately, by the gender of the speakers whose rates they are judging! Moreover, inasmuch as the speech rates of the male and female speakers were very similar, it does not seem as if the results can be attributed to greater decoder accuracy on the part of the female judges (Hall, 1985). In the present study, the rates of the three female speakers were judged to be slower than the rates of the male speakers, despite the fact that the actual average speech rate of the female speakers was but a trifle higher than that of the male speakers. 


\section{GENERAL DISCUSSION}

The results of the two experiments indicate that listener gender is involved in the perception of speech rate and that the gender of the speakers is also involved. One inference, then, that might be made from the results of both experiments is that, if the perception of a speaker's tempo influences the listener's evaluation of that speaker, then males and females may evaluate the same speakers differently because of their differing perceptions of the speakers' tempos. It may be, for example, in light of the finding by Miller et al. (1976), that males are perceived to be more persuasive, knowledgeable, intelligent, and objective than females (even when they speak at the same rate) by virtue of their speech rates' being perceived to be faster than those of females.

The effect sizes $\left(r^{2} s\right)$ in both studies are sufficient to indicate that the roles of listener and, particularly, speaker gender in the perception of speech rate are not at all trivial (Rosenthal \& Rosnow, 1984). It seems fair to conjecture, then, that although person perception may be mediated by speech rate, the perception of speech rate is mediated by gender and, thus, that person perception is mediated by both speech rate and gender. It is interesting that, despite the present-day concern with gender effects noted earlier, in no published studies of speech rate and person perception has gender been used as a variable. As recently as 1982 , Street and Brady declared in a footnote that "Male voices were employed because the vast majority of speech rate studies have done so and assumed generalizability to female voices as well"' (p. 298). Indeed, they asserted in the same footnote, seemingly as justification for the omission of female voices, that in one study they found female voices to yield results "inconsistent with earlier research." The present results strongly suggest that the omission of gender may seriously limit our understanding of the processes involved in person perception.

\section{REFERENCES}

ANDERSON, S. W., \& JAFFE, J. (1990). Speaking rate predicts antidepressant response. In New Research Abstracts of the 143rd Annual Meeting of the American Psychiatric Association (p. 209). Washington, DC: American Psychiatric Association.

APPLE, W. (1981). A schema-based model for integrating visual and vocal cues. Unpublished manuscript, Columbia University, Department of Psychology.

Apple, W., Streeter, L.A., \& Krauss, R. M. (1979). Effects of pitch and speech rate on personal attributions. Journal of Personality \& Social Psychology, 37, 715-727.

BoND, R. N., \& FELDSTEIN, S. (1982). Acoustical correlates of the perception of speech rate: An experimental investigation. Journal of Psycholinguistic Research, 11, 539-557.

Bond, R. N., Feldstein, S., \& Simpson, S. (1988). Relative and absolute judgments of speech rates from masked and content-standard stimuli: The influence of vocal frequency and intensity. Human Communication Research, 14, 548-567.

BouRHIS, R. Y., \& GiLes, H. (1977). The language of intergroup distinctiveness. In H. Giles (Ed.), Language, ethnicity, and intergroup relations (pp. 119-136). London: Academic Press.

Brown, B. R. (1980). Effects of speech rate on personality attributions and competency ratings. In H. Giles, P. Robinson, \& P. Smith (Eds.), Language: Social psychological perspectives. Oxford, U.K.: Pergamon.

Brown, B. R., Strong, W. J., \& Rencher, A. C. (1974). Fifty-four voices from two: The effects of simultaneous manipulations of rate, mean fundamental frequency, and variance of fundamental frequency on ratings of personality from speech. Journal of the Acoustical Society of America, 55, 313-318.

Dembroski, T. M., \& MacDougall, J. M. (1983). Behavioral and psycho-physiological perspectives on coronary-prone behavior. In T. M. Dembroski, T. H. Schmidt, \& G. Blumchen (Eds.), Biobehavioral bases of coronary heart disease (pp. 106-129). New York: Karger.
Dohm, F.-A., Feldstein, S., \& Crown, C. (1988). Global speech rate and gender as mediating factors in person perception. Journal of the Acoustical Society of America, 83 (Suppl. 1), S68. (Abstract)

EAGLY, A. H. (1983). Gender and social influence: A social psychological analysis. American Psychologist, 38, 971-981.

EYSENCK, S., \& EYSENCK, H. (1963). On the dual nature of extraversion. British Journal of Social \& Clinical Psychology, 2, 46-55.

Feldstein, S., Crown, C. L., \& JAFFe, J. (1991). Expectation and extraversion: Influencing the perceived rate of tone-silence sequences. Bulletin of the Psychonomic Society, 29, 395-398.

Feldstein, S., \& Sloan, B. (1984). Actual and stereotyped speech tempos of extraverts and introverts. Journal of Personality, 52, 188-204.

Goldman-EISler, F. (1968). Psycholinguistics: Experiments in spontaneous speech. New York: Academic Press.

Grosjean, F., \& LANE, H. (1974). Effects of two temporal variables on the listener's perceptions of reading rate. Journal of Experimental Psychology, 102, 893-896.

HALL, J. (1985). Male and female nonverbal behavior. In A. W. Siegman \& S. Feldstein (Eds.), Multichannel integrations of nonverbal behavior (pp. 195-226). Hillsdale, NJ: Erlbaum.

Kearns, L., \& FeldStein, S. (1987, April). The role of speech rate and loudness in cardiovascular responsivity. Paper presented at the meeting of the Eastern Psychological Association, Arlington, VA.

Miller, N., Maruyama, G., Beaber, R. J., \& Valone, K. (1976). Speed of speech and persuasion. Journal of Personality \& Social Psychology, 34, 615-624.

Murray, H. A. (1943). Thematic Apperception Test. Cambridge, MA: Harvard University Press.

Rosenthal, R., \& RosNow, R. L. (1984). Essentials of behavioral research: Methods and data analysis. New York: McGraw-Hill.

SCHERER, K. R. (1974). Acoustic concomitants of emotional dimensions: Judging affects from synthesized tone sequences. In S. Weitz (Ed.), Nonverbal communication (pp. 105-111). New York: Oxford University Press.

SCHERER, K. R. (1978). Inference rules in personality attribution from voice quality: The loud voice of extraversion. European Journal of Social Psychology, 8, 467-487.

SCHUCKER, B., \& JACOBS, D. R. (1977). Assessment of behavioral risk of coronary disease by voice characteristics. Psychosomatic Medicine, 39, 229-240.

Siegman, A. W., Feldstein, S., Tommaso, C. T., Ringel, N., \& LatING, J. (1987). Expressive vocal behavior and the severity of coronary artery disease. Psychosomatic Medicine, 49, 545-561.

Smith, B. L., Brown, B. R., Strong, W. J., \& RenCHER, A. C. (1975). Effects of speech rate on personality perception. Language \& Speech, 18, 145-152.

Street, R. L., JR., \& Brady, R. M. (1982). Speech rate acceptance ranges as a function of evaluative domain, listener speech rate, and communication context. Communication Monographs, 49, 290-308.

Street, R. L., JR., Brady, R. M., \& Putnam, W. (1983). The influence of speech rate stereotypes and rate similarity on listeners' evaluations of speakers. Journal of Language \& Social Psychology, 2, 37-56.

TAJFEL, H. (ED.) (1982). Social identity and intergroup relations. Cambridge: Cambridge University Press.

\section{NOTE}

1. The Thematic Apperception Test (TAT) consists of a set of 31 pictures that are used to assess the dynamics of personality functioning. The 10 women whose speech samples were used in this study were among those who used, in Feldstein and Sloan's (1984) study, the same three cards in the "natural speech" condition.

(Manuscript received June 1, 1993.) 